\title{
Editorial \\ Contextualized Behavior for Improving Managerial and Entrepreneurial Decision-Making
}

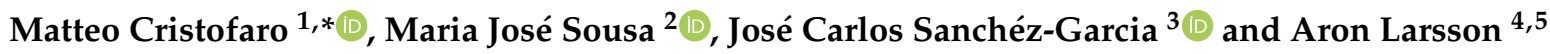 \\ 1 Department of Management and Law, Faculty of Economics, University of Rome, 00185 Roma, Italy \\ 2 Department of Political Science and Public Policies, Instituto Universitário de Lisboa (ISCTE-IUL), \\ 1649-026 Lisboa, Portugal; mjdcsousa@gmail.com \\ 3 Department of Social Psychology, University of Salamanca, 37008 Salamanca, Spain; jsanchez@usal.es \\ 4 Department of Computer and Systems Sciences, Stockholm University, SE-164 07 Kista, Sweden; \\ aron@dsv.su.se \\ 5 Department of Information Systems and Technology, Mid Sweden University, SE-851 70 Sundsvall, Sweden \\ * Correspondence: matteo.cristofaro@uniroma2.it
}

check for updates

Citation: Cristofaro, Matteo, Maria José Sousa, José Carlos Sanchéz-Garcia, and Aron Larsson. 2021. Contextualized Behavior for Improving Managerial and Entrepreneurial Decision-Making. Administrative Sciences 11: 14. https://doi.org/10.3390/admsci 11010014

\section{Academic Editor:}

Isabel-María Garcia-Sanchez

Received: 7 February 2021

Accepted: 8 February 2021

Published: 10 February 2021

Publisher's Note: MDPI stays neutral with regard to jurisdictional claims in published maps and institutional affiliations.

Copyright: (c) 2021 by the authors. Licensee MDPI, Basel, Switzerland. This article is an open access article distributed under the terms and conditions of the Creative Commons Attribution (CC BY) license (https:// creativecommons.org/licenses/by/ $4.0 /)$.
Since the conceptualization of bounded rationality by Herbert Simon (1947), management scholars started investigating how people-managers and entrepreneurs-really make decisions within (and for) organizations. Taking into considerations the effect on organizational choices (e.g., new product development, market entry, merger and/or acquisition of other entities) and related performance (in organizational, economic, and social terms), a series of trends have flourished within this pivotal research area. Nowadays, the main important are: the biasing or beneficial role of heuristics (i.e., cognitive shortcuts of human mind) (Kahneman 2003), the influence of socio-demographic characteristics and personality traits (see the derived Upper Echelons Theory; Hambrick and Mason 1984; Abatecola and Cristofaro 2020), the impact of affective states (e.g., emotions, mood, temperament), the intertwinement between cognitive and emotional factors, the co-determinant role of the (micro-, meso-, and macro-) environment in the formation of choices with person-, group-, firm-specific variables, and the biasing or beneficial impact of technologies on managers' and entrepreneurs' rationality.

The aim of the proposed Special Issue is to deeply investigate these trends in conceptual and/or empirical terms, trying to provide new insights on how managers and entrepreneurs make decisions within and for organizations. Research direction followed were: (a) The analysis of the differential role of affective states in managerial and entrepreneurial decisions (Baron 2008; Zhang and Cueto 2017), as the emotions are a driver for motivation regarding goals achievement, and impacts the nature of the decision (Cristofaro 2019); (b) differential cognitive schemas of managers and entrepreneurs (Forbes 1999; Cristofaro 2020); (c) the features of new technologies (e.g., big data analytics) that help or undermine decision-making processes (Sundberg and Larsson 2017); (d) dilemmas of organizational culture regarding the possibility of reducing the negative influences of cognitive traps (Hammond et al. 1998; Bazerman and Moore 2013); (e) heuristics conditions that are beneficial for managers and/or entrepreneurs during the organizational development processes; (f) the stronger or weaker impact of the personality of managers/entrepreneurs on decisions respect to their affective states (Armstrong et al. 2012), (g) the role of competences and experiences in the learning and decisions paths (Sousa et al. 2019; Sánchez-García et al. 2017); (g) which heuristics are beneficial for "take the plunge decisions" of entrepreneurs; (h) the differences in emotions in individual and group decisions; and (i) the impact of cognition and/or affective states of stakeholders on the one of managers and entrepreneurs (Hodgkinson and Sadler-Smith 2018).

The Special Issue of Administrative Sciences entitled "Managerial and entrepreneurial decision making: Emerging issues" received 16 submissions from March 2020 to October 2020. Among them, only 7 have been accepted to be published (acceptance rate $43 \%$ ) after 
the one-blind peer-review process. Published manuscripts were considered having scientific soundness and originality, but, especially, leading to the advancement of managerial and entrepreneurial decision-making literature.

About the entrepreneurial decision-making process, the study of Arend (2020) entitled "Getting Nothing from Something: Unfulfilled Promises of Current Dominant Approaches to Entrepreneurial Decision-Making" makes a provokable debates on the value of two dominant models in the decision-making process in the entrepreneurial context: the creative school, and the logic of effectuation. In particular, departing from the weaknesses and failures of the of these two models, he then provides a series of alternative approaches for effectively studying the entrepreneurial decision-making. The first approach states that the origins of the resources are not identifiable; they are windfalls that occur at different stages of the process and with different possible effects. From this, the role that managers-entrepreneurs have in the identification of resources, as well as in their use, stands out. The second approach also considers heterogeneous factors as windfalls and explicitly recognizes that other companies are endowed with them as well, which should lead to progress through co-evolutionary action. This alternative provides more open roles for managers and more meaning for institutional policy purposes to support business decision-making. The third alternative they propose takes a different starting point. It is aimed at the premises of the formal theories that underlie the currently dominant approaches. Provided critiques offer the basis to identify spaces for improvement, to warn from applying prescriptions that rely on models' current weaknesses and flaws, and to outline the opportunities of three different alternative approaches in studying entrepreneurial decision-making.

As to extend the analysis of the entrepreneurial decision-making process, this was also investigated by a third party view, in particular, from the consultants' standpoint. Indeed, Nuijten et al. (2020), with their work entitled "Cognitive Biases in Critical Decisions Facing SME Entrepreneurs: An External Accountants' Perspective," examined biases in entrepreneurial decision-making from the perspective of SME accountants. To this aim, they conducted an empirical study by interviewing 14 accountants who can provide independent assessments of small medium enterprise (SME) decision-making regarding strategy, regulatory compliance, human resources, IT, and succession. Results show that the presence of a particular bias is highly dependent on decision domain as well as accountants showed four different approaches (warn, inform, intervene, and coach) when they encounter cognitive biases in entrepreneurial decision-making. In this study, therefore, the role of the context in which a decision is made emerges as pivotal because of the emergence of distinct biases. As to reduce the probability of falling in these biases, authors propose that accountants must intervene in highlighting the cognitive pitfalls to SME entrepreneurs as well as that extensive programs of feedback to combat biases should be implemented.

This conclusion is shared also by the work of Schettini et al. (2020) entitled "Enhancing Healthcare Decision-Making Process: Findings from Orthopaedic Field." In particular, they intended to analyze, through an interview-based explorative case study, whether and how cognitive biases occurring in "clinical reasoning" can affect orthopedists in decision-making regarding the follow-up after knee and hip arthroplasty. Results from the semi-structured face-to-face interviews conducted with three orthopedic surgeons attested the presence of four common biases (affect heuristic, anchoring, halo effect, saliency), and four others (groupthink, availability, overconfidence, confirmation) that come to light depending on the physicians' intrinsic working experience and/or working context (i.e., private or public hospital). From that, decision-making of physicians can be improved through the intervention of a third party that can evaluate the process according to the context in which it is embedded. The amelioration of decision-making processes, therefore, may come through the involvement of a third party and practices of training and coaching.

Above results are also in line with the work by Goldsby et al. (2020), who proposed a conceptual paper entitled “Under Pressure: Time Management, Self-Leadership, and 
the Nurse Manager." The work advances a model to help mitigating time pressure on nurse managers and their frontline nurses based on the research regarding time pressure, psychosocial care, time management, and self-leadership. In particular, by the use of the metatriangulation methodology, authors propose three metaconjectures. First, it is proposed that time pressure will impede good decision-making and detract from the provision of quality psychosocial care by nurse managers. Second, research on time management and self-leadership leads authors to conjecture that when practices in these two areas are successfully implemented, the negative effect of time pressure on decisions related to care can be reduced. Third, the proper application of time management and self-leadership practices moderates the relationship between time pressure and psychosocial care by nurse managers. They conclude that deliberate and persistent use of time management and self-leadership practices, stimulated by training and coaching, may reduce the dissatisfiers that drain time and energy on the unit and open up more opportunities to find the little fixes that add marginal time savings as well.

However, biases in decision-making processes are just an effect of inner antecedents of decision-makers (e.g., personality traits, affective states, etc.,) and, because of that, another effective strategy to prevent cognitive biases is to understand their link with these precursory factors. In this regard, the study by Cristofaro et al. (2020) entitled "The Influence of Core Self-Evaluations on Group Decision Making Processes: A Laboratory Experiment" deals with the consideration of the personal trait called Core Self-Evaluations (CSE) - thus, the evaluations that individuals make about others, the world, and themselves-in decisionmaking processes. In particular, CSE of respondents was investigated with regard to: (i) the duality intuitive vs. reflective thinking, (ii) the connection with the overconfidence bias, and (iii) decision-making performance. To this aim, 120 graduate students-divided into groups of four-took part in a simulation game and were asked to make decisions acting the role of General Manager of a small-sized manufacturing firm. Results show that an average level of CSE is preferable to balance intuitive and reflective thinking, as well as avoiding overconfidence bias and reaching the best performance possible. This work suggests that there is a huge misattribution in considering a high level of CSE as being beneficial for decision-making processes and consequent performance and, because of that, managers should be aware of the level of CSE of each individual composing groups as to reach effective results.

In parallel to the study of the contextual features and personal characteristics that can lead to advent of biases in decision-making processes, other studies have been more focused on the actions to be implemented for anticipating undesired decision outcomes. In this vein, the paper by Splichalova et al. (2020) entitled "Managerial Decision Making in Indicating a Disruption of Critical Infrastructure Element Resilience," proposed a conceptual model to preventively indicate a potential disruption of the critical infrastructure elements' resilience before the actual occurrence of the adverse event. They identify the lack of managerial tools for the purpose of providing process support to decision-making in the selection of indicators for resilience disruptions, and contributes with a discussion on the need to further address resilience disruptions in the protection of critical infrastructure. In particular, they propose a model that consists of eight interconnected steps, providing the assessor with comprehensive instructions for the indication of a possible disruption of the resilience of critical infrastructure elements. This enables the assessment of the current level of the element's resilience to disruptive events evaluated according to the available methods.

With the same rationale of Splichalova et al. (2020), the work by Brous and Janssen (2020) entitled "Trusted decision-making: Data governance for creating trust in data science decision outcomes" provided a thoughtful model to understand the role of data governance in creating trust in data science decision outcome. In particular, owing to the duality of technology lens and the adoption of two explanatory case studies in the asset management domain, authors are able to depict the interactions among the organization, decisionmakers, and technology. Propositions of the model establish that organizations with an 
established data governance capability are more likely to: (i) have a well-functioning data science capability, (ii) to generate trusted data science outcomes, (iii) to ensure that organizational conditions of data science are met, (iv) and manage organizational and process changes introduced by data science outcomes. In synthesis, data governance here emerges as a boundary condition for managing the organizational consequences of data science outcomes.

In total, this special issue covers the topic of managerial and entrepreneurial decisionmaking from a multitude of important perspectives that have flourished within the area. From the published papers it clearly emerges that the original concepts and theories, e.g., bounded rationality and the presence of cognitive biases in human decision-making processes, still play an important role in contemporary research (e.g., Shepherd and Rudd 2014; Artinger et al. 2015; Cristofaro 2017, 2020).

In this regard, from a systematic evaluation of the 7 published papers, the following can be stated: as to improve their decision-making process (i.e., by reducing biases and consequently improve related performance), executives and entrepreneurs should contextualize their behavior. Indeed, the works by Schettini et al. (2020) and Nuijten et al. (2020) demonstrate how decision-makers should be aware of the context in which they implement their actions; this is because the surrounding environment can drive to different biases for which the same preventive action cannot work. However, due to the strong influence of psychological factors for the elaboration of decisions, such as a high Core Self-Evaluation personality trait (see Cristofaro et al. 2020), executives and entrepreneurs should implement behavioral strategies, such as improving (through coaching and/or training) their own self-leadership (Goldsby et al. 2020) in order to adaptively act and react within organizations. In this regard, executives and entrepreneurs must be ecologically rational, thus be aware of the negative and positive effects that biases can have depending on the context and use them at their advantage (Gigerenzer et al. 1999).

In sum, it is here taken the position that behavior is the function of the strategies (e.g., heuristics) that individuals choose from the set of all possible ones (i.e., toolbox) according to the environment in which these strategies should be implemented (Todd and Brighton 2016). However, also planning and organizing activities-such as elaborating models that can prevent adverse organizational events (Splichalova et al. 2020) or defining activities that can help authority and control over the management of data assets (Brous and Janssen 2020)—can also help anticipating/avoiding undesired decision outcomes. From that, managerial and entrepreneurial decision-making emerge, even more, as phenomena that cannot be detached from the environment in which executives and entrepreneurs are embedded, claiming to establish new approaches to research (Arend 2020) that looks at decision-making as an individual/group/organization-environment dialectical and multi-level phenomenon.

Author Contributions: All authors contributed equally to each section of this Editorial. All authors have read and agreed to the published version of the manuscript.

Conflicts of Interest: The authors declare no conflict of interest.

\section{References}

Abatecola, Gianpaolo, and Matteo Cristofaro. 2020. Hambrick and Mason's “Upper Echelons Theory": Evolution and Open Avenues. Journal of Management History 26: 116-36. [CrossRef]

Arend, Richard J. 2020. Getting nothing from something: Unfulfilled promises of current dominant approaches to entrepreneurial decision-making. Administrative Sciences 10: 61. [CrossRef]

Armstrong, Steven J., Eva Cools, and Eugene Sadler-Smith. 2012. Role of cognitive styles in business and management: Reviewing 40 years of research. International Journal of Management Reviews 14: 238-62. [CrossRef]

Artinger, Florian, Malte Petersen, Gerd Gigerenzer, and Jurgen Weibler. 2015. Heuristics as adaptive decision strategies in management. Journal of Organizational Behavior 36: S33-S52. [CrossRef]

Baron, Robert A. 2008. The role of affect in the entrepreneurial process. Academy of Management Review 33: 328-40. [CrossRef]

Bazerman, Max H., and Don Moore. 2013. Judgment in Managerial Decision Making, 5th ed. New York: Wiley. 
Brous, Paul, and Marijin Janssen. 2020. Trusted decision-making: Data governance for creating trust in data science decision outcomes. Administrative Sciences 10: 81. [CrossRef]

Cristofaro, Matteo. 2017. Herbert Simon's bounded rationality: Its evolution in management and cross-fertilizing contribution. Journal of Management History 23: 170-90. [CrossRef]

Cristofaro, Matteo. 2019. The role of affect in management decisions: A systematic review. European Management Journal 37: 6-17. [CrossRef]

Cristofaro, Matteo. 2020. "I feel and think, therefore I am": An Affect-Cognitive Theory of management decisions. European Management Journal 38: 344-55. [CrossRef]

Cristofaro, Matteo, Pier Luigi Giardino, and Luna Leoni. 2020. The influence of core self-evaluations on group decision making processes: A laboratory experiment. Administrative Sciences 10: 29. [CrossRef]

Forbes, Daniel P. 1999. Cognitive approaches to new venture creation. International Journal of Management Reviews 1: 415-39. [CrossRef]

Gigerenzer, Gerg, Peter M. Todd, and the ABC Research Group. 1999. Simple Heuristics that Make Us Smart, 1st ed. New York: Oxford University Press.

Goldsby, Elizabeth, Michael Goldsby, Christopher B. Neck, and Christopher P. Neck. 2020. Under pressure: Time management, self-leadership, and the nurse manager. Administrative Sciences 10: 38. [CrossRef]

Hambrick, Donald C., and Phyllis A. Mason. 1984. Upper echelons: The organization as a reflection of its top managers. Academy of Management Review 9: 193-206. [CrossRef]

Hammond, John S., Ralph Keeney, and Howard Raiffa. 1998. The hidden traps in decision making. Harvard Business Review 76: 47-58. [PubMed]

Hodgkinson, Gerard, and Eugene Sadler-Smith. 2018. The dynamics of intuition and analysis in managerial and organizational decision making. Academy of Management Perspectives 32: 473-92. [CrossRef]

Kahneman, Daniel. 2003. A perspective on judgment and choice: Mapping bounded rationality. American Psychologist 58: 697-720. [CrossRef]

Nuijten, Arno, Nick Benschop, Antoniette Rijsenbilt, and Kristinka Wilmink. 2020. Cognitive Biases in Critical Decisions Facing SME Entrepreneurs: An External Accountants' Perspective. Administrative Sciences 10: 89. [CrossRef]

Sánchez-García, José C., Elena Rodriguez-Gómez, Brizeida R. Hernández-Sánchez, and José Maniel Pérez-Díaz. 2017. Entrepreneurship Education as a Key Antecedent to Boost Nascent Entrepreneurs. In Nascent Entrepreneurship and Successful New Venture Creation. Edited by Antonio Carrizo Moreira, Dantas J. Guilherme Leitã and Fernando Manuel Valente. Hershey: IGI Global, pp. 58-84.

Schettini, Irene, Gabriele Palozzi, and Antonio Chirico. 2020. Enhancing healthcare decision-making process: Findings from orthopaedic field. Administrative Sciences 10: 94. [CrossRef]

Shepherd, Neil G., and John M. Rudd. 2014. The influence of context on the strategic decision-making process: A review of the literature. International Journal of Management Reviews 16: 340-64. [CrossRef]

Simon, Herbert. 1947. Administrative Behavior. New York: The Macmillan Company.

Sousa, Maria J., Manuel Carmo, Ana Cristina Gonçalves, Rui Cruz, and Jorge M. Martins. 2019. Creating knowledge and entrepreneurial capacity for HE students with digital education methodologies: Differences in the perceptions of students and entrepreneurs. Journal of Business Research 94: 227-40. [CrossRef]

Splichalova, Alena, David Patrman, Nikol Kotalova, and Martin Hromada. 2020. Managerial decision making in indicating a disruption of critical infrastructure element resilience. Administrative Sciences 10: 75. [CrossRef]

Sundberg, Leif, and Aron Larsson. 2017. The impact of formal decision processes on e-government projects. Administrative Sciences 7: 14. [CrossRef]

Todd, Peter M., and Henry Brighton. 2016. Building the theory of ecological rationality. Minds and Machines 26: 9-30. [CrossRef]

Zhang, Stephen X., and Javier Cueto. 2017. The study of bias in entrepreneurship. Entrepreneurship Theory and Practice 41: 419-54. [CrossRef] 